\title{
PREVALÊNCIA DA DOENÇA DE PARKINSON RELACIONADA AO AUXÍLIO-DOENÇA DA PREVIDÊNCIA SOCIAL
}

Daliane Cristina dos Santos, Emília Pio da Silva. Prevalência da doença de Parkinison relacionada ao auxílio-doença da previdência social. Revista Saúde Dinâmica, vol. 2, núm.2, 2020. Faculdade Dinâmica do Vale do Piranga.

\section{SAÚDE DINÂMICA - Revista Científica Eletrônica FACULDADE DINÂMICA DO VALE DO PIRANGA}

4a Edição 2020 | Ano II-no 2 | ISSN - 2675-133X 


\title{
Prevalência da doença de Parkinson relacionada ao auxílio-doença da previdência social.
}

\section{Prevalence of parkinson's disease related to social security aid.}

\author{
Daliane Cristina dos Santos ${ }^{1}$, Emília Pio da Silva ${ }^{2}$ \\ ${ }^{1}$ Graduada em Fisioterapia pela Faculdade Dinâmica do Vale do Piranga, Rua G, lote 11, 205, Bairro Paraíso, \\ Ponte Nova, $M G$ \\ ${ }^{2}$ Professora do Curso de Fisioterapia da Faculdade Dinâmica do Vale do Piranga, Rua G, lote 11, 205, Bairro \\ Paraíso, Ponte Nova, MG. Autor correspondente: emiliapiosilva@yahoo.com.br.
}

\section{Resumo}

A doença de Parkinson (DP) é uma enfermidade neurodegenerativa incurável que gera incapacidades físicas ao indivíduo acometido, afetando sua qualidade de vida, autonomia e independência. Quantificar a prevalência da DP relacionada ao auxílio-doença previdenciário concedido pela Previdência Social, no período entre 2008 e 2017. Trata-se de uma pesquisa descritiva e quantitativa, realizada por meio da base de dados da Previdência Social, através do Acompanhamento Mensal do Benefício Auxílio-Doença Previdenciário no período entre janeiro de 2008 a dezembro de 2017. Os dados obtidos foram digitalizados em planilha eletrônica do Excel e os resultados gerais foram expressos em porcentagem e apresentados em gráficos e tabela. Resultados: No período entre 2008 e 2017 houve uma concessão de 13.899 auxílios-doença decorrentes da DP, tendo um aumento de 36,98\% nesses 10 anos. O maior número de benefícios concedidos pela Previdência Social ocorreu no ano de 2017, com 1.737 beneficiários, e o maior índice em porcentagem de concessão foi no período de 2015-2016, com 33,67\% . Já a maior redução ocorreu no período de 2014-2015, com um decréscimo de 10,81\%. Dentre os meses analisados de cada ano, destacou-se o mês junho de 2016, com 198 casos de benefícios concedidos pela Previdência Social. O processo de envelhecimento pode ser um dos fatores que levam ao surgimento da DP e, nesse sentido, o aumento da população idosa poderá estar relacionado ao aparecimento de mais pessoas acometidas pela DP. Dessa forma, o número de assegurados que irão necessitar do benefício auxílio-doença poderá aumentar, gerando um impacto no sistema previdenciário.

Palavras chave: Doença de Parkinson. Auxílio-doença. Previdência Social.

\begin{abstract}
Parkinson's disease (PD) is an incurable neurodegenerative disease that generates physical disabilities for the affected individual, affecting their quality of life, autonomy and independence. Objective: To quantify the prevalence of PD related to the social security sickness benefit granted by Social Security, in the period between 2008 and 2017. Materials and methods: This is a descriptive and quantitative research, carried out through the Social Security database, through the Monthly Monitoring of the Social Security Assistance-Illness Benefit in the period between January 2008 and December 2017. The data obtained were digitized in an Excel spreadsheet and the general results were expressed as a percentage and presented in graphs and table. Results: In the period between 2008 and 2017, 13,899 sickness benefits resulting from PD were granted, with an increase of $36.98 \%$ in these 10 years. The largest number of benefits granted by Social Security occurred in 2017, with 1,737 beneficiaries, and the highest rate in percentage of concession was in the 2015-2016 period, with 33.67\%. The greatest reduction occurred in the 2014-2015 period, with a decrease of $10.81 \%$. Among the analyzed months of each year, June 2016 stood out, with 198 cases of benefits granted by Social Security. Conclusion: The aging process can be one of the factors that lead to the emergence of PD and, in this sense, the increase in the elderly population may be related to the appearance of more people affected by PD. Thus, the number of policyholders who will need the sickness benefit may increase, generating an impact on the social security system.
\end{abstract}

Key Words: Parkinson's disease, Sickness allowance, Social Security. 


\section{INTRODUÇÃO}

A Doença de Parkinson (DP) é uma enfermidade neurológica que foi descrita por James Parkinson (1755-1824) em 1817, sendo intitulada como "Paralisia agitante". Foi definida como: "Movimento involuntário trêmulo, com força muscular diminuída, em partes não ativas, mesmo quando suportadas; com uma propensão de curvatura do tronco para frente e aceleração do ritmo da caminhada: com sentidos e intelecto permanecendo ilesos" (LEREBOULLET; BUSSARD, 1884, APUD BERRIOS, 2016, p. 115).

Considera-se o Parkinson como uma enfermidade neurodegenerativa mais presente em idosos. Sua prevalência aumenta dez vezes mais após os 60 anos de idade, embora a ocorrência de casos na quarta ou quinta década de vida venha se ampliando progressivamente e acometendo cerca de $10 \%$ das pessoas com idade inferior a 45 anos (WEINTRAUB; COMELLA; HORN, 2008, apud PIEMONTE, 2013).

Segundo Ministério da Saúde, estima-se que, no Brasil, existam aproximadamente 200 mil pessoas diagnosticadas com a DP e que cerca $1 \%$ da população mundial, a partir dos 65 anos, seja acometida por esta enfermidade (BRASIL, 2017b). Há uma prevalência de 100 a 200 casos de DP por 100.000 habitantes, sendo que a incidência e a prevalência aumentam com a idade (TANNER; HUBBLE; CHAN, 1996, apud BRASIL, 2010).

A etiologia ainda é desconhecida, porém, acredita-se que há o envolvimento de fatores predisponentes genéticos e fatores tóxicos, tanto ambientais quanto endógenos, provenientes do próprio metabolismo celular neuronal, resultando nas alterações neurodegenerativas e na deficiência dopaminérgica (BARBOSA, 2004).

Sabe-se que essa doença ocorre devido à degeneração das células da substância negra. Essas células são responsáveis pela produção da dopamina, que interfere na condução dos estímulos nervosos; a sua falta ou diminuição acarreta prejuízos aos movimentos e gera os sintomas característicos da doença, sendo diferente a sua progressão entre os pacientes, por se tratar de um processo demorado, e sem rápidas ou dramáticas mudanças (BRASIL, 2015b).

Segundo Pinheiro e Barbosa (2016), os principais sinais da DP são o tremor de repouso, a bradicinesia, a rigidez e a instabilidade postural, sendo o tremor a manifestação clínica mais frequente de acordo com Barbosa (2004), ocorrendo principalmente quando o 
membro está em repouso e cessando quando há o movimento voluntário. Sua intensidade é aumentada quando exposto a situações de estresse, e desaparece durante o sono, sendo os movimentos rítmicos dos dedos das mãos, a forma mais característica (PINHEIRO; BARBOSA, 2016).

$\mathrm{Na}$ DP, os músculos tornam-se mais tensos e contraídos, resultando na rigidez muscular plástica, identificada no deslocamento passivo dos membros, pescoço e tronco, podendo o movimento acontecer de forma entrecortada, conhecido como "roda denteada" (PINHEIRO; BARBOSA, 2016).

Entende-se como bradicinesia a lentidão na execução do movimento. O paciente com Parkinson apresenta diminuição da movimentação espontânea, diminuição da expressão facial e alteração da escrita, podendo a mesma ser trêmula, de tamanho reduzido e menos legível. O desempenho para a realização das atividades de vida diária (AVD’s) também fica comprometido devido à necessidade de maior esforço e de maior tempo para serem concretizadas (BARBOSA, 2004).

As alterações dos reflexos posturais levam a um aumento da incidência de quedas decorrentes da instabilidade postural, e, com a evolução da doença, poderão gerar, no indivíduo, incapacidades para se levantar ou se manter de pé sem auxílio (PINHEIRO; BARBOSA, 2016).

Além dos sintomas motores, podem surgir manifestações neurológicas, psíquicas e sistêmicas. Alguns desses sintomas são: depressão, sialorréia, tonturas, dores e distúrbios tanto cognitivos e respiratórios, quanto da fala e do sono. A ocorrência e intensidade podem variar de um paciente para o outro, podendo gerar desconforto e incapacidade, e por isso demandam ser analisadas igualmente e de forma cuidadosa, para um tratamento com uma abordagem terapêutica adequada (BARBOSA, 2004).

As consequências da DP têm um grande efeito sobre as atividades relacionadas ao trabalho, principalmente quando se descobre o diagnóstico em idade precoce. Muitas pessoas são diagnosticadas após a aposentadoria, outras, no entanto, são diagnosticadas ainda na fase produtiva, o que, com o avançar da doença, resultará em dificuldades no trabalho. Em alguns casos, a aposentadoria é imposta aos trabalhadores com idade ativa devido à enfermidade (VALCARENGHI et al., 2018).

Os sintomas da patologia causam limitações e dificuldades aos pacientes, que geralmente passam a demandar o auxílio financeiro da Previdência Social para custear sua 
sobrevivência. Este tipo de benefício é concedido de forma temporária ao segurado, que fica incapacitado por motivo de doença (BRASIL, 2017a). Nestas condições enquadram-se aquelas pessoas acometidas por doença crônica, como, por exemplo, o Parkinson. De acordo com a Lei 8213/91, no art. $1^{\circ}$, os beneficiários por meio de contribuição serão assegurados pela Previdência Social por motivo de incapacidade, idade avançada, desemprego involuntário, tempo de serviço, encargos familiares e prisão ou morte daqueles de quem dependiam economicamente. Analisando a referida lei, pode-se inferir que o portador da DP se insere na categoria de beneficiários assegurados pela Previdência Social, desde que preencha os pré-requisitos necessários, como carência de filiação e contribuição, e atestado por meio de perícia médica.

De acordo com Alves (2018), a DP atinge, principalmente, idosos a partir dos 60 anos ou mais e, com o aumento crescente da expectativa de vida global, o número de indivíduos acometidos pela enfermidade tende a aumentar no futuro. Diante deste cenário o aumento na expectativa de vida poderá influenciar no aumento na concessão de benefícios por auxíliodoença, visto que o Parkinson gera incapacidades físicas no indivíduo.

Considerando os impactos que a DP pode causar no cotidiano das pessoas, este estudo objetivou quantificar a prevalência da DP relacionada aos Benefícios auxílio-doença previdenciários concedidos pela Previdência Social, no período entre 2008 e 2017.

\section{MATERIAIS E MÉTODOS}

\section{TIPO DE PESQUISA}

Trata-se de uma pesquisa descritiva e quantitativa. De acordo com Andrade (2010), na pesquisa descritiva é feita a observação dos fatos para depois serem registrados, analisados, classificados e interpretados, sem que haja a alteração dos dados. Ou seja, os elementos são estudados, mas não podem ser manipulados pelo pesquisador. Já a pesquisa quantitativa tem como enfoque estratificar as amostras, resumindo os dados de forma numérica e tabulandoos, conforme os objetivos que se pretende alcançar. Os resultados são determinados e apresentam menor chance de erros de interpretação. Em alguns casos são elaborados índices para facilitar o entendimento da informação (MARCONI; LAKATOS, 2011). 


\section{BASE DE DADOS UTILIZADA}

A pesquisa foi realizada por meio da base de dados da Previdência Social. Os dados são oriundos das Informações Estatísticas Relativas à Segurança e Saúde Ocupacional, especificamente o Acompanhamento Mensais dos Benefícios Auxílio-Doença Previdenciários Concedidos, encontrado na Classificação Estatística Internacional de Doenças e Problemas Relacionados com a Saúde (Cógido G20; CID-10) no período entre janeiro de 2008 e dezembro de 2017. O referido código corresponde a DP. O marco cronológico da pesquisa pautou-se nos Anuários disponíveis no site da Previdência Social, sendo o período de tempo selecionado suficiente para compreender a relação existente entre a DP e os índices de benefícios de auxílio-doença concedidos no Brasil, nos últimos 10 anos, possibilitando o entendimento do desempenho das variáveis analisadas.

\section{ANÁLISE DOS DADOS OBTIDOS}

Os dados obtidos foram digitalizados em planilha eletrônica do Microsoft Excel (2016) de forma descritiva para extrair informações associadas à frequência, à média e à disseminação dos dados, sendo analisados posteriormente de acordo com as variáveis do programa. Para facilitar a compreensão e visualização dos resultados gerais, os mesmos foram expressos em porcentagem e apresentados em gráficos e tabela.

\section{RESULTADOS E DISCUSSÃO}

No período entre 2008 e 2017 a Previdência Social concedeu 13.899 auxílios-doença decorrentes da DP, sendo que nestes 10 anos houve um aumento de 36,98\% na concessão desses benefícios. Pode-se afirmar que tal dado pode ser explicado pelo aumento da prevalência de DP na população brasileira, uma vez que, a cada indivíduo diagnosticado, há probabilidade do benefício ser concedido.

O cotidiano da pessoa com DP é marcado por diversas frustações, uma vez que o indivíduo convive diariamente com os altos e baixos da doença, vivendo sempre um dia 
diferente do outro. A realidade desse paciente é configurada por melhora ou piora dos tremores, da rigidez e dos demais sinais e sintomas, além da ingestão de diversos medicamentos em razão de outras comorbidades, o que pode causar efeitos colaterais que podem gerar desconforto e sofrimento. Diante disso, o portador dessa afecção vive uma constante luta para superar as limitações impostas a cada dia em virtude da manutenção da autonomia e da independência (VALCARENGHI et al., 2018).

Com o passar do tempo as implicações físicas podem levar à redução da força muscular, repercutindo no decréscimo do condicionamento físico e gerando impactos sobre o estado mental, social e econômico dos portadores e de seus familiares (PAULA, 2006, apud PETERNELLA; MARCON, 2009). Diante disso o portador da DP necessita de um tratamento e acompanhamento médico visando à qualidade de vida, necessitando do auxiliodoença para suprir os gastos gerados com a doença.

A respeito da realização das atividades cotidianas, as pessoas com DP devem criar estratégias de modificação, visto que o indivíduo não consegue ter o mesmo desempenho para a sua execução como antes da doença e tais alterações podem ser marcantes na vida dessas pessoas. Os desconfortos sucedidos da doença impactam na realização das tarefas do cotidiano, que ocorrem com mais dificuldade e de forma mais lenta e com o avançar da doença, o portador da DP passa a necessitar de auxílio de familiares ou cuidadores. Essas limitações impostas pela doença podem causar o isolamento do indivíduo, gerando baixa autoestima e podendo levar a um quadro depressivo (VALCARENGHI et al., 2018).

O portador da DP não tem outra opção a não ser abandonar sua atividade laboral, o que implica na necessidade de receber o auxílio financeiro do governo em virtude da sua manutenção e de sua família. Considerando tal realidade, o Gráfico 1 apresenta o número de benefícios concedidos pela Previdência Social a pessoas portadoras de DP nos últimos anos, nos períodos analisados. O maior número de benefícios concedidos pela Previdência Social ocorreu no ano de 2017, sendo concedidos 1.737 auxílios-doença, que segundo Brasil (2017a) representou mais de $40 \%$ dentre todas as concessões de benefícios. O segundo maior aumento ocorreu no ano de 2016 com 1.687 benefícios, seguidos pelo ano de 2012, com 1444 casos, e 2014, com 1415 ocorrências. 
Gráfico 1 - Número de Benefícios Concedidos pela Previdência Social a Portadores de DP nos últimos 10 anos.

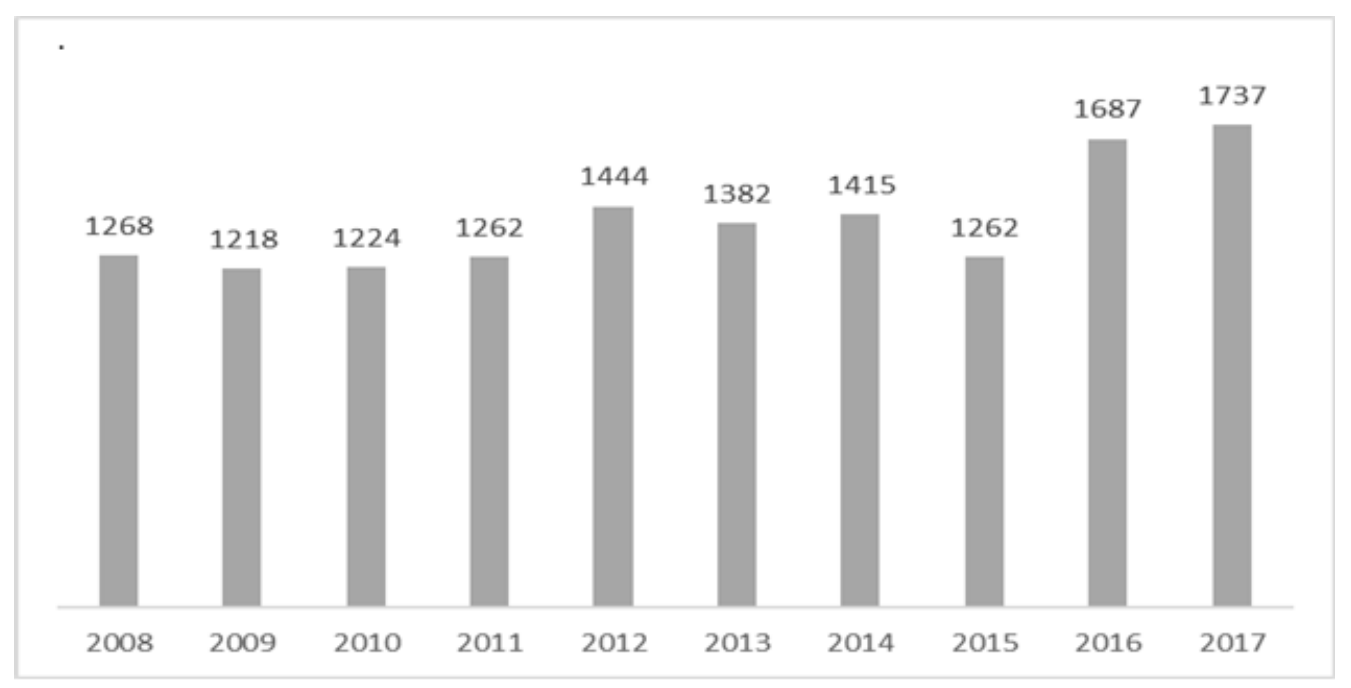

Fonte: Brasil (2018).

A Tabela 1 apresenta a porcentagem de beneficios concedidos desde o ano de 2008 até o ano de 2017. Dentre os períodos analisados, observou-se que o maior índice em porcentagem de benefícios concedidos foi no período de 2015-2016, com 33,67\%, e o segundo maior aumento aconteceu no período de 2011-2012, com 14,42\%. Nesta mesma tabela é possível conferir os índices de redução na concessão de benefícios, destacando-se o período de 2014-2015, em que ocorreu a maior redução com um decréscimo de $10,81 \%$. A segunda maior queda refere-se ao período de 2012-2013, com 4,29\%. Tal tendência corrobora os dados de Brasil (2016), visto que em 2016, de um modo geral, houve um aumento na concessão de benefícios auxílio-doença. Já no ano de 2015 observou-se uma redução dos benefícios em comparação com o ano de 2014 (BRASIL, 2015a). Acredita-se que tais tendências possam estar relacionadas com o envelhecimento populacional visto que, a cada ano, eleva-se a porcentagem de pessoas idosas na população brasileira - algumas delas portadoras de DP. 
Tabela 1 - Porcentagem de Aumento e Redução dos Benefícios Concedidos pela Previdência Social a Portadores de DP nos Últimos 10 anos.

\begin{tabular}{c|c|c}
\hline Ano & $\begin{array}{c}\text { \% Aumento } \\
\text { dos Benefícios }\end{array}$ & $\begin{array}{c}\text { \% Redução } \\
\text { dos } \\
\text { benéficos }\end{array}$ \\
\hline $2008-2009$ & & 3,94 \\
\hline $2009-2010$ & 0,49 & \\
\hline $2010-2011$ & 3,10 & \\
\hline $2011-2012$ & 14,42 & 4,29 \\
\hline $2012-2013$ & & 10,81 \\
\hline $2013-2014$ & 2,38 & \\
\hline $2014-2015$ & & 3 \\
\hline $2015-2016$ & 33,67 & \\
\hline $2016-2017$ & & \\
\hline
\end{tabular}

Fonte: Brasil (2018).

Em 2012, a população acima de 60 anos era composta de 25,4 milhões, e nos últimos cinco anos houve um aumento de 4,8 milhões de idosos, o que superou a marca dos 30,2 milhões em 2017, correspondendo a um crescimento de 18\% desse grupo etário, que vem aumentando cada vez mais no Brasil (IBGE, 2018a).

Estima-se que em 2047 a população do país irá aumentar chegando a 233,2 milhões de pessoas, ocorrendo uma redução nos próximos anos até atingir 228,3 milhões em 2060. Dentre essas estimativas, acredita-se que em 2060 a população com 65 anos ou mais de idade chegará a 58,2 milhões de idosos - cerca de 25,5\%, o que representará um quarto da população, sendo que em 2018 essa porcentagem era de 9,2\% (IBGE, 2018b).

O envelhecimento populacional, por um lado, trouxe os benefícios de uma maior longevidade, porém, aumentou a ocorrência de doenças crônico-degenerativas, ocasionando em um perfil de morbimortalidades (US NATIONAL INSTITUTE OF AGING, 2011, apud PIMENTA et al., 2015). Dentre essas doenças que atingem as pessoas idosas, a DP é uma das mais comuns, devido ao processo de envelhecimento que resulta na perda neural progressiva à medida que a idade progride.

Nesse sentido, entre os dados obtidos, o Gráfico 2 apresenta os meses com maior concessão de benefícios nos últimos 10 anos, em que destacou-se o mês junho de 2016, com 198 casos de benefícios concedidos pela Previdência Social, seguido pelo mês de agosto de 2017, com 177 beneficiários, e abril de 2015, com 165 beneficiários. 
Gráfico 2 - Meses com Maior Concessão de Benefícios da Previdência Social a Portadores de DP nos últimos 10 anos.

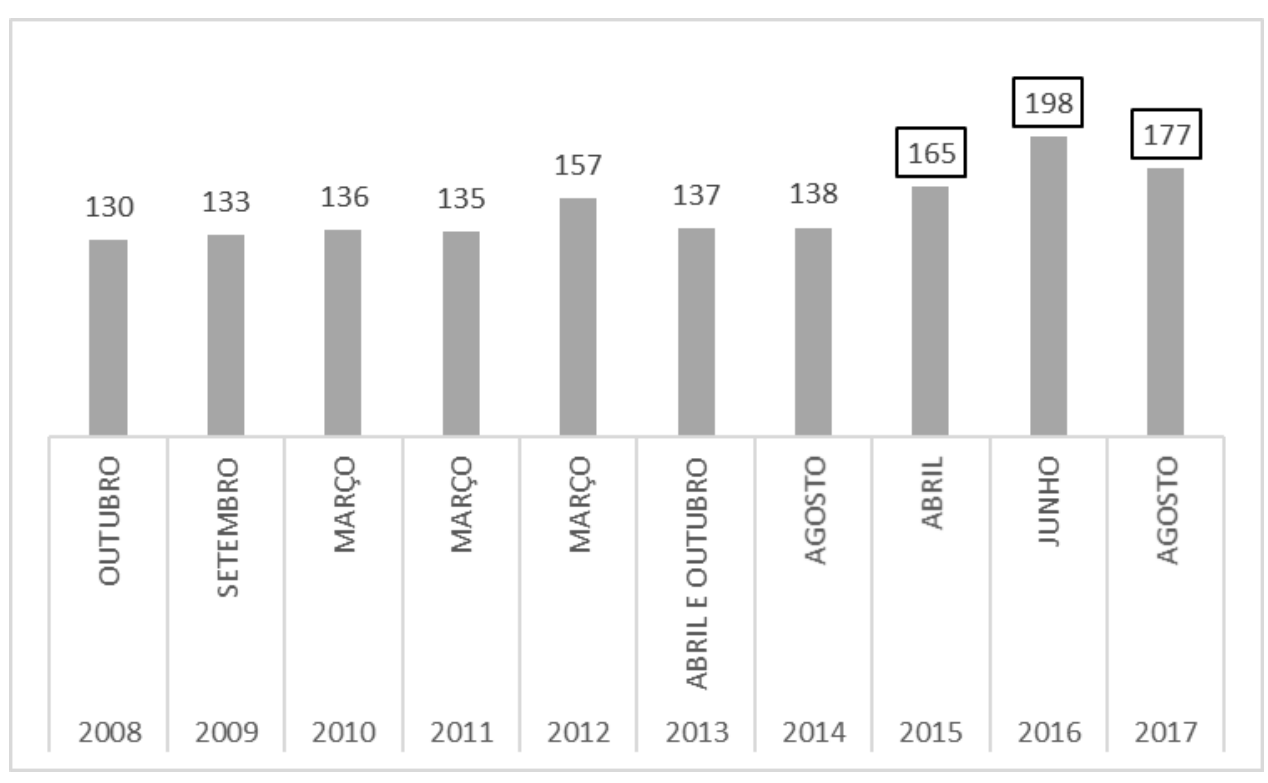

Fonte: Brasil (2018)

Observando o Gráfico 2, verificou-se que, de um modo geral, a concessão de benefícios vem aumentando a cada ano, independente do mês. Deste modo, a concessão dos benefícios pode ajudar a demonstrar que a DP não está relacionada com a sazonalidade, ou seja, com um determinado período ou época do ano.

A DP é considerada uma enfermidade idiopática, pois não há uma etiologia definida, sendo inexistente o fator pelo qual um indivíduo contrai essa doença, pois não se conhece o motivo que provoque a morte celular nigral (TEIVE, 2006, apud GALHARDO; AMARAL; VIEIRA, 2009). Contudo, o avançar da doença leva à redução da capacidade para o trabalho. Além disso, o processo de envelhecimento propicia a aceleração da perda de neurônios dopaminérgicos com o decorrer dos anos, o qual tem relação direta sobre esta patologia (REBELLATO et al., 2006, apud SOUZA et al., 2011).

Esses pacientes são os únicos que utilizam a maioria dos serviços de saúde, necessitando de medicação para o resto de suas vidas. Eles também estão mais propensos às internações em hospitais devido à sua condição, dependendo de cuidados em casa, além de adaptações em seu domicílio para a convivência e segurança. Se o indivíduo estiver em sua fase produtiva, o custo que será gerado para a sociedade pode durar um longo tempo, 
aumentando a demanda de cuidados na saúde (BOVOLENTA; FELÍCIO, 2016). Nesse sentido, o benefício auxílio-doença é uma garantia financeira para o portador da DP.

Os portadores da DP, principalmente os de baixa renda, enfrentam diversas dificuldades, entre as quais se encontra o elevado custo para manutenção do tratamento e que, muitas vezes, é inadequado ou insuficiente, havendo restrições quanto às indicações de tratamentos e terapias. Existe muita objeção para a aquisição dos medicamentos, além da necessidade de acompanhamento de psicólogo, fonoaudiólogo, fisioterapeuta e nutricionista. Diante disso, questiona-se: como os portadores da DP, que recebem apenas um salário mínimo, podem sobreviver e ter acesso a um tratamento adequado frente a uma doença que exige o uso de diversos medicamentos e acompanhamento terapêutico multiprofissional? A baixa renda acaba prejudicando a qualidade de vida dessas pessoas, impossibilitando o retardo da progressão da doença, uma vez que os sintomas acabam gerando outros malefícios (BRASIL, 2018).

Neste sentido, a concessão ou manutenção do benefício previdenciário por incapacidade tem como objetivo manter a proteção, o zelo e, principalmente, a dignidade do ser humano diante das condições socioeconômicas (FONSECA, 2011). Dessa forma, o auxílio-doença se torna importante, pois é um benefício que vai garantir financeiramente o beneficiário que se encontra incapaz por motivo de doença em seu tratamento médico, acesso a medicamentos e até mesmo outros serviços de saúde dos quais o indivíduo necessita. Assim, ressaltar a importância do benefício para o portador de DP não implica afirmar que o mesmo é suficiente para manutenção dos custos do tratamento.

O Parkinson é uma doença progressiva, que ocasiona incapacidade grave após 10 a 15 anos, gerando um alto impacto tanto social quanto financeiro, principalmente na população mais idosa. Estima-se que o gasto anual com medicamentos antiparkinsonianos no mundo esteja em torno de 11 bilhões de dólares, cujo tratamento se torna mais caro na fase avançada da doença em cerca de 3 a 4 vezes mais (DODEL et al., 1998, SIDEROWF et al., 2000, apud BRASIL, 2010).

O aumento da população idosa está associado ao aumento do uso de medicamentos, devido às doenças crônicas, visto que esses sujeitos utilizam em média de dois a cinco medicamentos (GLYNN et al., 2011, apud COLET; BORGES; AMADOR, 2016). Dentre os medicamentos que possuem maior custo mensal está incluído o antiparkinson. Tais 
medicamentos geram um custo elevado, considerando a renda do idoso, o que pode limitar a sua aquisição em estabelecimentos farmacêuticos privados.

Nesse cenário, se os idosos com renda baixa fossem adquirir todos os medicamentos prescritos em estabelecimentos privados, a sua renda familiar seria comprometida em 5,7\% e 10,0\%, respectivamente (COLET; BORGES; AMADOR, 2016), já que fazem uso de muitos medicamentos, os quais nem sempre são disponibilizados pelo sistema público de saúde.

De modo complementar, os gastos econômicos com a DP podem se elevar, tendo em vista a hospitalização, medicamentos e reabilitação, além da necessidade de cuidados domiciliares devido à perda de produtividade, gerando assim uma diminuição da renda familiar (DOWDING; SHENTON; SALEK, 2006, apud PETERNELLA; MARCON, 2012).

Ao considerar a renda atual da pessoa idosa no Brasil como sendo o salário mínimo estabelecido em R \$ 998,00, desde janeiro de 2019 (BRASIL, 2019), verifica-se que tal rendimento é insuficiente para os gastos com saúde.

Segundo Barros (2000 apud MENDES et al., 2005), os idosos cujos ciclos produtivos encontram-se comprometidos ficam na expectativa de receber uma aposentadoria garantida pelo sistema previdenciário, que na maioria das vezes se torna escassa para prover todas as suas necessidades de sobrevivência. Isto acarreta prejuízos sobre a qualidade de vida, bem como de sua saúde, que são resultantes da redução da renda mensal.

Este cenário, que está estritamente ligado à atual questão previdenciária, vem provocando abundante pressão sobre os sistemas estruturados que, em sua grande maioria, foram organizados para responder a uma realidade marcada pela extensão do emprego assalariado e pelo ligeiro período de aposentadoria. Diante disso, a preocupação aumenta quando se pensa no decréscimo do número de contribuintes e com o aumento do número de aposentados (LONGINO JR, 2000, apud BATISTA et al., 2008).

De acordo com Costa et al. (2011), o envelhecimento populacional acarretará aumento do custo de financiamento da seguridade social e, ao mesmo tempo, terá redução da oferta de trabalho; com isso, implicará na sustentabilidade previdenciária que enfrentará a possível diminuição das receitas vinculadas aos salários e o aumento da demanda por benefícios de aposentadoria e pensão. À medida que cresce a parcela de idosos, aumenta o desequilíbrio do atual sistema previdenciário. 
Sendo assim, devido ao fato de que o processo de envelhecimento possa estar relacionado a um dos fatores que levam ao surgimento da DP e que, nesse sentido, o aumento da população idosa poderá estar ligado ao aparecimento de mais pessoas acometidas pela DP, o número de assegurados que irão necessitar do benefício auxílio-doença poderá aumentar. Diante desse fato, o sistema previdenciário precisará estar preparado para um possivel aumento no número de assegurados que poderão surgir com o passar do tempo e assim garantir a concessão a todos os beneficiários.

\section{CONCLUSÃO}

Verificou-se que o processo de envelhecimento impacta no surgimento de diversas doenças crônicas, entre elas o Parkinson. Com o aumento da população idosa a cada ano, também poderá surgir novos casos de DP, aumentando a proporção de pessoas acometidas e causando um possível impacto no sistema previdenciário, que terá de arcar com o aumento do número de assegurados que necessitarão do benefício auxílio-doença previdenciário. $\mathrm{O}$ auxíliodoença se torna imprescindível para o portador da DP, uma vez que esse benefício irá ajudar a manter os gastos utilizados no tratamento que visa o retardo da progressão da doença, podendo proporcionar ao indivíduo uma melhor qualidade de vida.

No estudo realizado entre o período de 2008 e 2017 houve uma concessão de 13.899 auxílios-doença decorrentes da DP, tendo um aumento de 36,98\% nestes 10 anos. Considerando as lacunas científicas da temática abordada, este estudo evidenciou a necessidade de outros estudos sobre a DP e as dificuldades enfrentadas pelos segurados do benefício do INSS frente ao atual sistema previdenciário do Brasil.

\section{REFERÊNCIAS}

ALVES, C. O que é Mal de Parkinson, Sintomas, Tratamento, Causas e Mais. OPAS, [s.l.] 17 abr. 2018. Disponível em: https://www.opas.org.br/o-que-e-mal-de-parkinson-sintomastratamento-causas-e-mais/. Acesso em: 22 jun 2019.

ANDRADE, M. M. Pesquisa científica: noções introdutórias. In: Introdução à metodologia do trabalho científico. 10. ed. São Paulo: Editora Atlas, 2010. p. 109-115.

BARBOSA, M. T. Doença de Parkinson em Idosos. In: SALDANHA, A. L.; CALDAS, C. P. 
Saúde do Idoso: A arte de cuidar. 2. ed. Rio de Janeiro: Interciência, 2004. p. 256-266.

BATISTA, A. S.; JACCOUD, L. B.; AQUINO, L.; EL-MOOR, P. D. Envelhecimento e dependência: desafios para a organização da proteção social. Brasília: MPS, SPPS, 2008. 160 p. - (Coleção Previdência Social; v. 28). Disponível em:

http://sa.previdencia.gov.br/site/arquivos/office/3_081208-173354-810.pdf. Acesso em: 22 jun 2019.

BERRIOS, G. E. Introdução à "Paralisia agitante", de James Parkinson (1817). Rev.

latinoam. psicopatol. fundam. São Paulo, v. 19, n. 1, p. 114-121, Mar. 2016. Disponível em: $<$ http://www.scielo.br/scielo.php?script=sci_arttext\&pid=S1415-

47142016000100114\&lng=en\&nrm=iso>. Acesso em: 19 jun 2020.

BRASIL. Câmara dos Deputados. Comissão de Defesa dos Direitos das Pessoas com Deficiência. Audiência Pública para tratar de assuntos pertinentes às Pessoas com a Doença de Parkinson. 07 junho 2018. Disponível em: https://www2.camara.leg.br/atividadelegislativa/comissoes/...parkinson/view\%20Em\%C2\%A0cache. Acesso em: 29 jul 2019.

BRASIL. Decreto fixa salário mínimo de R\$ 998 em 2019. 02 jan 2019. Disponível em: http://www.brasil.gov.br/noticias/emprego-e previdencia/2019/01/decreto-fixa-salario-minimo-de-r-998-em-2019. Acesso em: 30 jul 2019.

BRASIL. Lei no 8.213, de 24 de julho de 1991. Dispõe sobre os Planos de Benefícios da Previdência Social e dá outras providências. Diário Oficial da União. Brasília, DF, 25 jul.1991, P. 14809. Disponível em: http://www.planalto.gov.br/ccivil_03/leis/18213cons.htm. Acesso em: 26 jun 2019.

BRASIL. Ministério da Previdência Social. Anuário Estatístico da Previdência Social AEPS. 2015a. Brasília: MF/DATAPREV. Disponível em:

http://sa.previdencia.gov.br/site/2015/08/AEPS-2015-FINAL.pdf. Acesso em: 22 jun 2019.

BRASIL. Ministério da Previdência Social. Anuário Estatístico da Previdência Social AEPS. 2016. Brasília: MF/DATAPREV. Disponível em: http://sa.previdencia.gov.br/site/2018/08/aeps2016.pdf. Acesso em: 22 jun 2019.

BRASIL. Ministério da Previdência Social. Anuário Estatístico da Previdência

Social - AEPS. 2017a. Brasília: MF/DATAPREV. Disponível em: http://sa.previdencia.gov.b r/site/2019/04/AEPS-2017-abril.pdf. Acesso em: 22 jun 2019.

BRASIL. Ministério da Previdência Social. Tabelas CID - 10. Auxílios-doença acidentários e previdenciários concedidos segundo os códigos da Classificação Internacional de Doenças CID-10, 2018. Disponível em: http://www.previdencia.gov.br/dadosabertos/estatsticas/tabelas-cid-10/. Acesso em: 20 maio 2019.

BRASIL. Ministério da Saúde. Doença de Parkinson. 09 de setembro de 2015b. Disponível em: http://bvsms.saude.gov.br/dicas-em-saude/2059-doenca-de-parkinson. Acesso em: 26 jul 2019. 
BRASIL. Ministério da Saúde. Pacientes com Parkinson contarão com novos medicamentos no SUS. 17 de novembro de 2017b. Disponível em: http://www.saude.gov.br/noticias/agencia-saude/41873-pacientes-com-parkinsoncontarao-com-novos-medicamentos-no-sus. Acesso em: 28 jun 2019.

BRASIL. Ministério da Saúde. Portaria nº 228, de 10 de maio de 2010. Aprova o Protocolo Clínico e Diretrizes Terapêuticas - Doença de Parkinson. Diário

Oficial da União, Brasília, DF, 2010. Disponível em: http://bvsms.saude.gov.br/bvs/saudeleg is/sas/2010/prt0228_10_05_2010.html. Acesso em: 22 jun 2019.

BOVOlENTA, T. M.; FELICIO, A. C. O doente de Parkinson no contexto das Políticas Públicas de Saúde no Brasil. Einstein, São Paulo, v. 14, n. 3, p. 7-9, Set. 2016. Disponível em: http://www.scielo.br/pdf/eins/v14n3/pt_1679-4508-eins-14-03-0vii.pdf. Acesso em: 26 Jun 2019.

COLET, C. F.; BORGES, P. E. M.; AMADOR, T. A. Perfil de gastos com medicamentos entre idosos em diferentes grupos socioeconômicos. Rev. bras. geriatr. gerontol. Rio de Janeiro, v. 19, n. 4, p. 591-601, Ago. 2016. Disponível em: http://www.scielo.br/scielo.php?script=sci_arttext\&pid=S180998232016000400591\&lng=en\&nrm=iso. Acesso em: 28 Jun 2019.

COSTA, C. K. F.; JUNIOR, S. S. P.; MESQUITA, R. A.; MASSUDA, E. M. Envelhecimento populacional e a necessidade de reforma da saúde pública e da previdência social brasileiras. A Economia em Revista, v.19, n.2,

2011. Disponível em: https://www.researchgate.net/publication/277029266_Envelhecimento_ populacional_e_a_necessidade_de_reforma_da_saude_publica_e_da_previdencia_social_bras ileiras. Acesso em: 22 jun 2019.

GALHARDO, M. M. A. M. C.; AMARAL, A. K. F. J.; VIEIRA, A. C. C. Caracterização dos distúrbios cognitivos na Doença de Parkinson. Rev. CEFAC, São Paulo, 2009. v. 11, n. 2, p. 251-257. Disponível em: http://www.scielo.br/scielo.php?script=sci_arttext\&pid=S1516$18462009000600015 \& \operatorname{lng}=$ en\&nrm=iso. Acesso em: 26 jul 2019.

FONSECA, Rafaela Bortolatto Pinter da. Os benefícios por incapacidade com enfoque no princípio da dignidade da pessoa humana. Centro Universitário Barriga Verde - Unibave. 2011. Disponível em: http://www.uniedu.sed.sc.gov.br/wp-content/uploads/2014/01/RafaelaBortolotto-Pinter-da-Fonseca.pdf. Acesso em: 29 jul 2019.

\section{IBGE. Número de idosos cresce $18 \%$ em 5 anos e ultrapassa 30 milhões}

em 2017. Out. 2018a. Disponível em: https://agenciadenoticias.ibge.gov.br/agencianoticias/2012-agencia-de-noticias/noticias/20980-numero-de-idosos-cresce-18-em-5-anos-eultrapassa-30-milhoes-em-2017. Acesso em: 12 jul 2019.

IBGE. Projeção da População 2018: número de habitantes do país deve parar 
de crescer em 2047. Ago. 2018b. Disponível em: https://agenciadenoticias.ibge.gov.br/agenci a-sala-de-imprensa/2013-agencia-de-noticias/releases/21837-projecao-da-populacao-2018numero-de-habitantes-do-pais-deve-parar-de-crescer-em-2047. Acesso em: 12 jul 2019.

MARCONI, M. A.; LAKATOS, E. M. Metodologia Qualitativa e Quantitativa. In:

Metodologia Científica. São Paulo: Editora Atlas S.A, 2011. p. 269-291.

MENDES, M. R. S. S. B.; GUSMÃO, J. L.; FARO, A. C. M.; LEITE, R. C. B. O. A situação social do idoso no Brasil: uma breve consideração. Rev. Acta paul. enferm. São Paulo, v. 18, n. 4, p. 422-426, Dez. 2005. Disponível em:

http://www.scielo.br/scielo.php?script=sci_arttext\&pid=S0103-

$21002005000400011 \& \operatorname{lng}=$ en\&nrm=iso. Acesso em: 26 jul 2019.

PETERNELlA, F. M. N.; MARCON, S. S. Descobrindo a Doença de Parkinson: impacto para o parkinsoniano e seu familiar. Rev. bras. Enferm, Brasília, v.

62, n. 1, p.25-31, fev 2009. Disponível em: http://www.scielo.br/scielo.php?script=sci_arttext \&pid=S0034-71672009000100004\&lng=pt\&nrm=iso. Acesso em: 31 jul 2019.

PETERNELLA, F. M. N.; MARCON, S. S. Qualidade de vida de indivíduos com Parkinson e sua relação com tempo de evolução e gravidade da doença. Rev. Latino-Am.

Enfermagem, Ribeirão Preto, v. 20, n. 2, p. 384-391, Abr. 2012. Disponível em:

http://www.scielo.br/scielo.php?script=sci_arttext\&pid=S0104-

$11692012000200023 \& \operatorname{lng}=$ en\&nrm=iso. Acesso em: 26 jul 2019.

PIEMONTE, M. E. P. Tratamento da doença de parkinson e parkinsonismo. In: PERRACINI, M. R.; FLÓ, C. M. Funcionalidade e Envelhecimento. Rio de Janeiro: Guanabara Koogan, 2013. p. 403-413.

PIMENTA, F. B.; PINHO, L.; SILVEIRA, M. F.; BOTELHO, A. C. C. Fatores associados a doenças crônicas em idosos atendidos pela Estratégia de Saúde da Família. Ciênc. saúde coletiva, Rio de Janeiro, v. 20, n. 8, p. 2489-

2498, Ago 2015. Disponível em: http://www.scielo.br/scielo.php?script=sci_arttext\&pid=S14 13-81232015000802489\&lng=en\&nrm=iso. Acesso em: 28 Jun 2019.

PINHEIRO, J. E. S.; BARBOSA, M. T. Doença de Parkinson e Outros Distúrbios do Movimento em Idosos. In: FREITAS, E. V.; PY, L. Tratado de Geriatria e gerontologia. 4. ed. Rio de Janeiro: Guanabara Koogan, 2016. p. 360-370.

SOUZA, C. F. M.; ALMEIDA, H. C. P.; SOUSA, J. B.; COSTA, P. H.; SILVEIRA, Y. S.S.; BEZERRA, J. C. L. A Doença de Parkinson e o Processo de Envelhecimento Motor: Uma Revisão de Literatura. Rev. Neurocienc. 2011; v.

19. n. 4 .p. 718-723. Disponível em: http://revistaneurociencias.com.br/edicoes/2011/RN1904 /revisao\%2019\%2004/570\%20revisao.pdf. Acesso em: 26 jul 2019.

VALCARENGHI, R. V.; ALVAREZ, A. M.; SANTOS, S. S. C.; SIEWERT, J. S.; NUNES, S. F. L.; TOMASI, A. V. R. O cotidiano das pessoas com a doença de Parkinson. Rev. Bras. Enferm., Brasília, v. 71, n. 2, p. 272-279, Abr. 2018. Disponível em: 
http://www.scielo.br/scielo.php?script=sci_arttext\&pid=S0034-

$71672018000200272 \& \operatorname{lng}=$ en\&nrm=iso\&tlng=pt. Acesso em: 28 maio 2019.

\section{Declaração de Interesse}

Os autores declaram não haver nenhum conflito de interesse

\section{Financiamento}

Financiamento próprio

\section{Colaboração entre autores}

Daliane Cristina dos Santos: desenvolveu seu TCC, o qual deu base para o artigo. Participou desde o planejamento da pesquisa e na coleta de dados, bem como nas análises estatísticas dos dados, assim como na redação do artigo.

Emília Pio da Silva: foi orientadora do trabalho, apoiou no planejamento do estudo, orientou a coleta de dados, bem como apoiou na análise estatística e dos dados e na redação do artigo. 